\title{
The diagnostic accuracy of the hand-held Raman spectrometer for the identification of anti-malarial drugs
}

Benjamin J. Visser ${ }^{1,2}$, Sophia G. de Vries ${ }^{1,2}$, Emmanuel B. Bache², Janneke Meerveld-Gerrits ${ }^{1,4}$, Daniëlle Kroon 1,2, Jimmy Boersma ${ }^{1}$, Selidji T. Agnandji ${ }^{2,3}$, Michèle van Vugt ${ }^{1}$ and Martin P. Grobusch ${ }^{1,2,3^{*}}$

\begin{abstract}
Background: There is a need for accurate and field-applicable instruments for the evaluation of the quality of antimalarial drugs. The aim of this study was to determine the diagnostic accuracy of the NanoRam ${ }^{\circledR}$, a handheld Raman spectrometer (RS), to identify anti-malarial drugs.

Methods: In total, 289 anti-malarial drugs collected in a randomized field survey in Gabon were evaluated. The samples were compared with authentic products as supplied by the official manufacturer. To determine the sensitivity and specificity of the handheld NanoRam ${ }^{\circledR}$ spectrometer in the identification of anti-malarial drugs, a two-gate reversed-flow design was applied. The standards for reporting of diagnostic accuracy studies (STARD) were followed. The index test was the handheld RS. The reference test standards were thin layer chromatography and high performance liquid chromatography with ultraviolet photo diode array detection.

Results: The sensitivity [95 \% confidence interval $(95 \% \mathrm{Cl})$ ] and specificity of the RS to correctly identify an antimalarial drug were $100 \%$ (95\% Cl 94.9-100\%) and $96 \%$ (95\% Cl 92.3-99.0\%), respectively. The RS could not differentiate between different batches of the same product or different manufacturers of the same product. Intra-observer agreement for 289 samples was $100 \%$. The average time to conduct the RS was $15 \mathrm{~s}$ per sample compared to $45 \mathrm{~min}$ per sample for TLC.
\end{abstract}

Conclusion: The handheld RS holds promise as an easy-to-use, quick and field-applicable instrument for the evaluation of quality of anti-malarial drugs, potentially empowering pharmacists, drug inspectors and medical regulatory authorities.

Trial registration NTR4341 (Dutch Trial Registry)

\section{Résumé}

Contexte: Il est nécessaire d'avoir des outils de terrain fiables pour l'évaluation de la qualité des médicaments antipaludiques. Le but de cette étude était de déterminer la précision diagnostique de l'outil NanoRam ${ }^{\circledR}$, un spectromètre Raman portable (RS), pour identifier les principes actifs des antipaludiques.

Méthodes: Au total, 289 médicaments antipaludiques collectés lors d'une enquête aléatoire au Gabon ont été évalués. Les échantillons ont été comparés à des produits authentiques, tel que fourni par le fabricant officiel. Afin de déterminer la sensibilité et la spécificité du spectromètre NanoRam ${ }^{\circledR}$ portable dans l'identification des médicaments antipaludiques, une méthode à flux inversé à deux canaux'a été appliquée. Les normes pour la présentation des études

\footnotetext{
*Correspondence: m.p.grobusch@amc.uva.nl

${ }^{3}$ Institute of Tropical Medicine, University of Tübingen, Tübingen,

Germany

Full list of author information is available at the end of the article
} 
de précision de diagnostic ont été respectées. Le test de l'indice était le spectromètre NanoRam ${ }^{\circledR}$ portable. Les tests de référence étaient la chromatographie sur couche mince (TLC) et chromatographie liquide à haute performance avec détection à barrette de diodes photo à ultraviolets.

Résultats: La sensibilité [95\% intervalle de confiance (IC $95 \%$ )] et la spécificité de la RS pour identifier correctement un médicament antipaludique était de $100 \%$ (IC à $95 \%$ de 94,9 à $100 \%$ ) et $96 \%$ (IC à $95 \%$ de 92,3-99,0\%), respectivement. Le RS ne pouvait pas différencier entre différents lots du même produit ou provenant de différents fabricants. L'accord intra-observateur pour 289 échantillons était de $100 \%$. Le temps moyen pour effectuer la RS était de 15 secondes par échantillon par rapport à 45 min par échantillon pour la TLC.

Conclusion: Le spectromètre portable Raman est prometteur comme instrument de mesure, facile à utiliser, rapide et facilement applicable sur le terrain pour l'évaluation de la qualité des médicaments antipaludiques, facilitant le travail des pharmaciens, des inspecteurs de qualité des médicaments et des autorités de réglementation médicale.

Enregistrement de première instance NTR4341 (Dutch Trial Registry)

Keywords: Artemisinin combination therapy (ACT), Central Africa, Counterfeit, Drug quality, Falsified, Field survey, Gabon, Malaria, MEDQUARG, NanoRam ${ }^{\circledR}$, Sensitivity, Specificity, Raman spectroscopy

\section{Background}

Poor-quality, falsified (counterfeit), substandard and degraded anti-malarial drugs (for definitions see [1]) are important impediments to public health. Studies have highlighted the magnitude of the problem of poor quality anti-malarial drugs [2-8]. According to the latest World Health Organization's (WHO) estimates, released in December 2015, there were 214 million cases of malaria in 2015 and 438,000 deaths [9]. Early diagnosis and treatment with appropriate anti-malarial drugs are pivotal [10]. The WHO recommends artemisinin-based combination therapy (ACT) for the treatment of uncomplicated falciparum malaria [11-13]. Negative consequences arise from the use of poor-quality anti-malarial drugs. Anti-malarials with low amounts of active pharmaceutical ingredients (APIs) may cause increased morbidity and mortality [14]. An estimated 122,350 [interquartile range (IQR): 91,577-154,736] under-five malaria deaths are associated with the use of poor-quality anti-malarials, representing $3.75 \%$ (IQR: $2.81-4.75 \%$ ) of all under-five deaths in a sample of 39 countries [15]. However, these results should be interpreted with caution since there are large gaps in data prevalence of poor-quality anti-malarials $[3,16]$ and in case fatality rates [15]. As well, inadequately low concentrations of the APIs in poor-quality drugs may result in sub-therapeutic concentrations of the drug in patients, which may engender drug resistance [17]. Furthermore, the use of poor-quality anti-malarial drugs leads to significant socio-economic losses for patients and their kin, health-care systems and pharmaceutical industries producing the genuine product [18]. Societies can lose confidence in a pharmaceutical brand, drugs, pharmacies, and health-care providers [2].

The spread of poor-quality anti-malarial drugs increases the need for rapid detection of such medicines throughout the supply chain. The paucity of quality assurance laboratories in Africa with appropriate analytical capabilities (in terms of personnel and equipment) slows down the fight against poor-quality medicines. Several screening methods have been used, or have been investigated for use in screening drug quality in low-resource settings. The aim of a screening tool in drug quality surveys is to minimize the number of antimalarial drugs that will undergo reference-standard testing in a (resource-limited) laboratory. Furthermore, the ideal screening tool should be low-cost, easy-to-use (not requiring specialist training), sustainable (especially in humid and hot climates) and easy and affordable to be repaired (locally). Ideally, the integrity of the sample should be sustained. Moreover, the total cost of identifying a conspicuous sample should be economically balanced in relation to the screening survey as a whole. Semi-quantitative thin layer chromatography, which was further developed by the Global Pharma Health Fund (GPHF), "the Minilab ${ }^{\circledR}$, has been available since the past couple of years $[19,20]$. This technique is applicable in the field and relatively cheap (approx. $4500 €$ in 2014) but requires training, the use of chemicals, and is labourintensive [21]. It can be used to identify the API and can therefore be used as a screening tool to detect falsified medicines. It is, however, a semi-quantitative method and results should, therefore, be confirmed using more accurate methods, such as high-performance liquid chromatography (HPLC) [1].

Non-invasive (non-destructive) methods as a screening and identification tool of APIs have recently gained more scientific interest [22, 23]. A recent report evaluated the $\operatorname{TruScan}^{\circledR}$ Raman device (using inelastic light scattering) for testing pharmaceutical products in the field to detect falsified and substandard medicines [24]. 
Six pharmaceutical products were under investigation, including analgesics and antidiarrhoeal medicines. It was shown that it could detect falsified drugs, but was not able to discriminate between good-quality and sub-standard drugs. The possibilities of Raman spectroscopy as a fast and reliable screening method for the detection of falsified artesunate tablets were investigated before, with the Renishaw System-1000 ${ }^{\circledR}$ spectrometer (Wotton-underEdge, UK), connected to a conventional light microscope. The method was able to distinguish between genuine and falsified artesunate and to identify the composition of the falsified tablets [25]. It was demonstrated that the results of the Raman spectroscopy method were in agreement with those of colourimetric tests and of liquid chromatography-mass spectrometry of artesunate. The present study aims to explore the ability of Raman spectroscopy (RS) performed by the NanoRam ${ }^{\circledR}$ handheld device to identify anti-malarial drugs and to differentiate between similar anti-malarial drugs. The diagnostic accuracy (sensitivity and specificity) of RS was determined, compared to thin layer chromatography (TLC).

\section{Methods}

\section{Anti-malarial drugs tested}

The samples used in this pilot study were collected in a randomized field survey of anti-malarial drugs in Gabonese pharmacies [21], following the medicine quality assessment reporting guidelines (MEDQUARG) [1]. The randomized field survey was registered in advance (Trial registration number: NTR4341 [26]). Also, the costs of the present study are reported [27] (Additional file 1). Scientific clearance for the field survey was obtained from the Scientific Review Committee (SRC) of the Centre de Recherches de Médicales de Lambaréné (CERMEL), Albert Schweitzer Hospital (SRC number: 2013.11). The Ethical Committee of CERMEL decided that ethical approval of the field survey study was not required, as the study is a health care quality assurance study, no humans having been subjected to observation or intervention. The detailed methods were described earlier $[21,26]$. In brief, anti-malarial drugs were collected by local fieldworkers from randomly selected pharmacies. In total 432 samples were collected, of which 289 were tested in the present study. Not all samples could be tested with the handheld Raman spectrometer (RS) because no reference standards of all the anti-malarial drugs could be obtained from the producing pharmaceutical companies; or the dosage form was not suitable for the handheld RS (e.g., capsule instead of tablet or liquid form); or no material was left from the collected sample (Fig. 1). The following five anti-malarial drugs were evaluated: artemether-lumefantrine ( $\mathrm{AL}, \mathrm{n}=150)$, quinine $(\mathrm{Q}, \mathrm{n}=40)$, sulfadoxine-pyrimethamine (SP, $\mathrm{n}=38$ ), dihydroartemisinin-piperaquine (DHA-PQ, $\mathrm{n}=32$ ), and artesunate-SP (AS-SP, $n=31$ ). These anti-malarials were produced by multiple pharmaceutical companies (Table 1). For analytical purposes, paracetamol (also known as acetaminophen) $500 \mathrm{mg}$ [collected in the pharmacy of the Academic Medical Center (AMC)] was included since it is readily available and would be useful for studying the ability of the handheld RS to differentiate between different products.

\section{Reference test: thin-layer chromatography}

Detailed reference test methods have been described before [16]. GPHF Minilab ${ }^{\circledR}$ [20] was used to run semiquantitative thin-layer chromatography (TLC) and disintegration testing to measure the concentration of APIs. The samples failing the TLC test were analysed by HPLC, for confirmation. The MiniLab ${ }^{\circledR}$ protocols award products a 'pass' for TLC if $80 \%$ or more of the labelled active ingredient(s) is present. For fixed-dose combinations (e.g., AL) and SP, 'pass' was awarded only if both active ingredients met this standard. TLC is an accepted method to assess the quality of drugs [28-30].

\section{Index test}

The present study was conducted in June and July 2015 at the AMC, University of Amsterdam, The Netherlands. All the tests were carried out in similar environmental conditions of light ( \pm 500 Lux), humidity $(70 \%)$ and temperature $\left( \pm 21^{\circ} \mathrm{C}\right)$. The index test was conducted by BJV, the reference test by BJV and JMG (TLC) and H. Kaur, London School of Tropical Medicine and Hygiene, UK (HPLC). Inter-observer agreement was calculated for the TLC test, but not for the HPLC and index test. The researcher conducting the index test was not blinded to the outcome of the reference test. The index test and reference test are seldom perfect; therefore, the test reproducibility was calculated using the kappa, the intraobserver agreement [31]. All the index tests were conducted in duplicate.

\section{Index test: Raman spectrometry-technique}

Raman spectrometry (inelastic light scattering or "Raman scattering") is a light-scattering process in which the sample under examination is irradiated with intense monochromatic light; the light scattered from the specimen is analysed for frequency shifts (Fig. 2) [32]. This technique can be used to observe vibrational, rotational, and other low-frequency modes in a material [33]. Raman spectrometry is particularly sensitive to non-polar bonds (e.g., C-C single or multiple bonds) and less sensitive to polar bonds [22]. In chemistry, it is frequently used to provide a "fingerprint" by which a molecule can be identified [34]. 


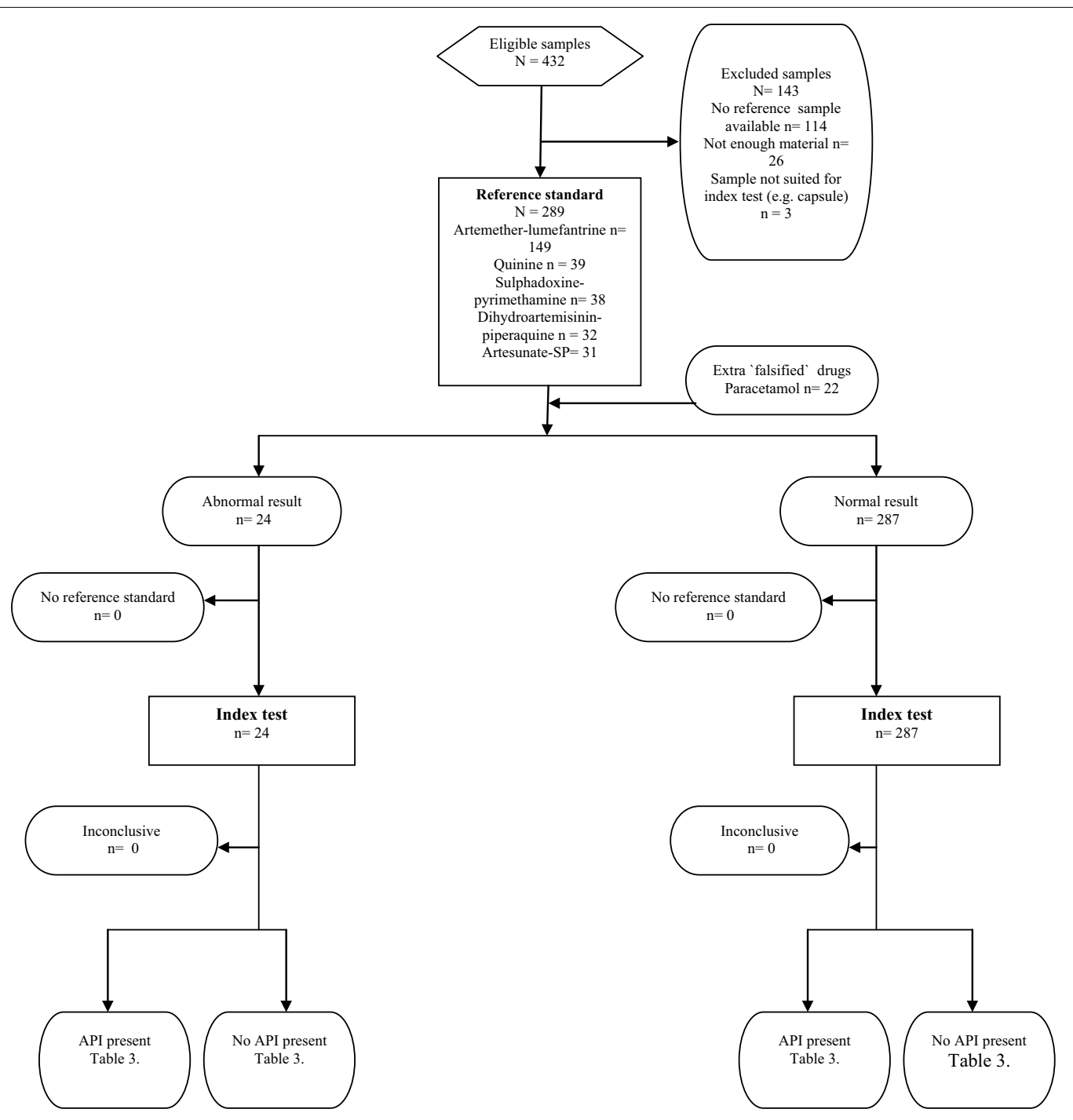

Fig. 1 STARD Flow diagram: identification of anti-malarials. This diagram scheme is found at http://www.consort-statement.org/flow_test.pdf

\section{Index test: equipment}

The NanoRam ${ }^{\circledR}$ hand-held RS was used in this study (Fig. 3). The device (model: BWS456, Serial Number: SAMLNA, manufactured in March 2014) was rented from B\&W Tek, Inc. 19 Shea Way, Newark, Delaware, USA, 19713). The $\operatorname{NanoRam}^{\circledR}$ is a hand-held Raman instrument for non-destructive identification and verification of materials such as APIs, excipients, intermediates and finished products (see Additional file 2 for specifications). The use of the device does not require any training, and handling can be managed by untrained non-specialist users. An advantage of this technique is that it can analyse drugs through transparent containers (blisters), maintaining the integrity of the sample. Raman spectroscopy is an approved method by the U.S. and European Pharmacopoeia [35], as well as the Pharmacopoeia of the People's Republic of China [36].

\section{Index test: factory calibration of the NanoRam ${ }^{\circledR}$}

The device used had been calibrated according to B\&W Tek, Inc. calibration procedures to a Raman shift accuracy of $\pm 4 \mathrm{~cm}^{-1}$. Standard calibration procedures included the creation of a calibration set using B\&W Tek, INc. SCL series Spectral Calibration Lamps (Mercury and Argon) and Polystyrene Calibration Cap. SCL 100 series Light Sources have a wavelength accuracy of $\pm 0.1 \mathrm{~nm}$. The spectral line data for Mercury ( $\mathrm{Hg})$ and Argon (Ar) are referenced in "Wavelength and transition probabilities for atomic ions, part 1 -wavelength", a 
Table 1 Summary of formulations tested with the brand name, dose, dosage form and manufacturer

\begin{tabular}{|c|c|c|}
\hline Pharmaceutical product & Generic name and dose & Manufacturer or distributor \\
\hline Arsiquinoforme ${ }^{\circledR}$ & Quinine tablet 250 mg & Sanofi Aventis \\
\hline Artediam $^{\circledR}$ & Artesunate-amodiaquine tablet 100/300 mg & Adams Pharmaceutical (Anhui) Co., Ltd \\
\hline \multirow[t]{2}{*}{ Artefan $^{\circledR}$} & Artemether-lumefantrine tablet 20/120 mg & Ajanta Pharma Ltd, India \\
\hline & Artemether-lumefantrine tablet 80/480 mg & \\
\hline Artim $^{\circledR}$ & Artemether-lumefantrine tablet 40/240 mg & Twight Litaka Pharma Limited Ltd, India \\
\hline \multirow[t]{2}{*}{ Artiz (Forte) ${ }^{\circledR}$} & Artemether-lumefantrine tablet 40/240 mg & Alice Pharma Pvt Ltd, India \\
\hline & Artemether-lumefantrine tablet 20/200 mg & \\
\hline Bimalaril $^{\circledR}$ & Artemether-lumefantrine tablet 80/480 mg & Bengba Pharmaceutical factory, China \\
\hline Coartem $^{\circledR}$ & Artemether-lumefantrine tablet 20/120 mg & Novartis Pharma, Netherlands \\
\hline Co-artemax ${ }^{\circledR}$ & Dihydroartemisinin-piperaquine tablet 40/320 mg & GA Pharma, Greece \\
\hline \multirow[t]{2}{*}{ Cofantrine $^{\circledR}$} & Artemether-lumefantrine tablet 20/120 mg & EGR Pharma, Luxembourg \\
\hline & Artemether-lumefantrine tablet 80/470 mg & \\
\hline $\operatorname{Colart}^{\circledR}$ & Artemether-lumefantrine tablet 20/120 mg & Glaxo Smith Kline Group \\
\hline Combimal $^{\circledR}$ & SP tablet 500/25 mg & Ajanta Pharma Ltd, Mauritius \\
\hline Darte-Q ${ }^{\circledR}$ & Dihydroartemisinin-piperaquine tablet 40/320 mg & Gosun Pharma Corp, China \\
\hline Duo-Cotecxin ${ }^{\circledR}$ & Dihydroartemisinin-piperaquine tablet 40/320 mg & Beijing Holley-Cotec Pharmaceutical Ltd, China \\
\hline Falquin ${ }^{\circledR}$ & Quinine tablet 300 mg & Plethico pharmaceutical Ltd, India \\
\hline Fansidar $^{\circledR}$ & SP tablet 500/25 mg & F.Hoffmann La Roche Ltd, Switzerland \\
\hline Lariam $^{\circledR}$ & Mefloquine tablet $250 \mathrm{mg}$ & F.Hoffmann La Roche Ltd, Switzerland \\
\hline \multirow[t]{2}{*}{ Lufanter ${ }^{\circledR}$} & Artemether-lumefantrine 20/120 mg & Bliss Gvs Pharma Ltd, India \\
\hline & Artemether-lumefantrine tablet 80/480 mg & \\
\hline \multirow[t]{2}{*}{ Lumart $^{\circledR}$} & Artemether-lumefantrine tablet 20/120 mg & Cipla Ltd, India \\
\hline & Artemether-lumefantrine tablet 40/240 mg & \\
\hline Malacur ${ }^{\circledR}$ & Dihydroartemisinin-piperaquine tablet 40/320 mg & Elder pharmaceuticals LTD, India \\
\hline Maloxine ${ }^{\circledR}$ & SP tablet 500/25 mg & Gracure Pharmaceuticals Ltd, India \\
\hline Mephaquin ${ }^{\circledR}$ & Mefloquine tablet $250 \mathrm{mg}$ & Mepha Ltd, Switzerland \\
\hline Paracetamol & Paracetamol tablet 500 mg & Actavis/Allergan, Netherlands \\
\hline P-Alaxin ${ }^{\circledR}$ & Dihydroartemisinin-piperaquine tablet 40/320 mg & Bliss Gvs Pharma Ltd, India \\
\hline Quinimax ${ }^{\circledR}$ & Quinine 500 and $125 \mathrm{mg}$ & Sanofi Aventis \\
\hline R-Lume ${ }^{\circledR}$ & Artemether-lumefantrine tablet 80/480 mg & Impact Healthcare Pvt Ltd, India \\
\hline Surquina ${ }^{\circledR}$ & Quinine tablet 250 mg & Laboratoire Innotech International, France \\
\hline
\end{tabular}

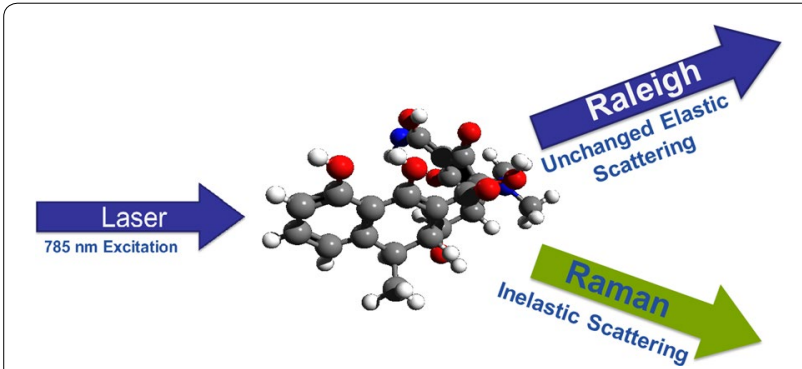

Fig. 2 Raman spectroscopy technique "inelastic light scattering"

publication of the National Standards Reference System, National Institute of Standards and Technology, U.S. Department of Commerce [37]. The calibration was conducted on 30-7-2014 and is valid for a year.
Index test: establishment of a spectral reference library The NanoRam ${ }^{\circledR}$ spectral device includes a library of 110 API's. However, no spectral references for anti-malarial drugs were provided with the NanoRam. Therefore, the spectra of different anti-malarial drugs which are known to be of good quality and which exhibit the variation (manufacturer, batch, crystal modification, particle size) typical of the anti-malarial to be analysed, were created using the instrument's built-in method without modification. For each reference spectrum, 20 runs (scans) are necessary. This spectrum or signature is used to compare with spectra of other test samples. In this study, only samples provided by the producing pharmaceutical company were considered as 'reference samples'. Libraries for different anti-malarial drugs and dosages were created (AL, DHA-PQ, Q, AS-SP, SP; for example libraries 


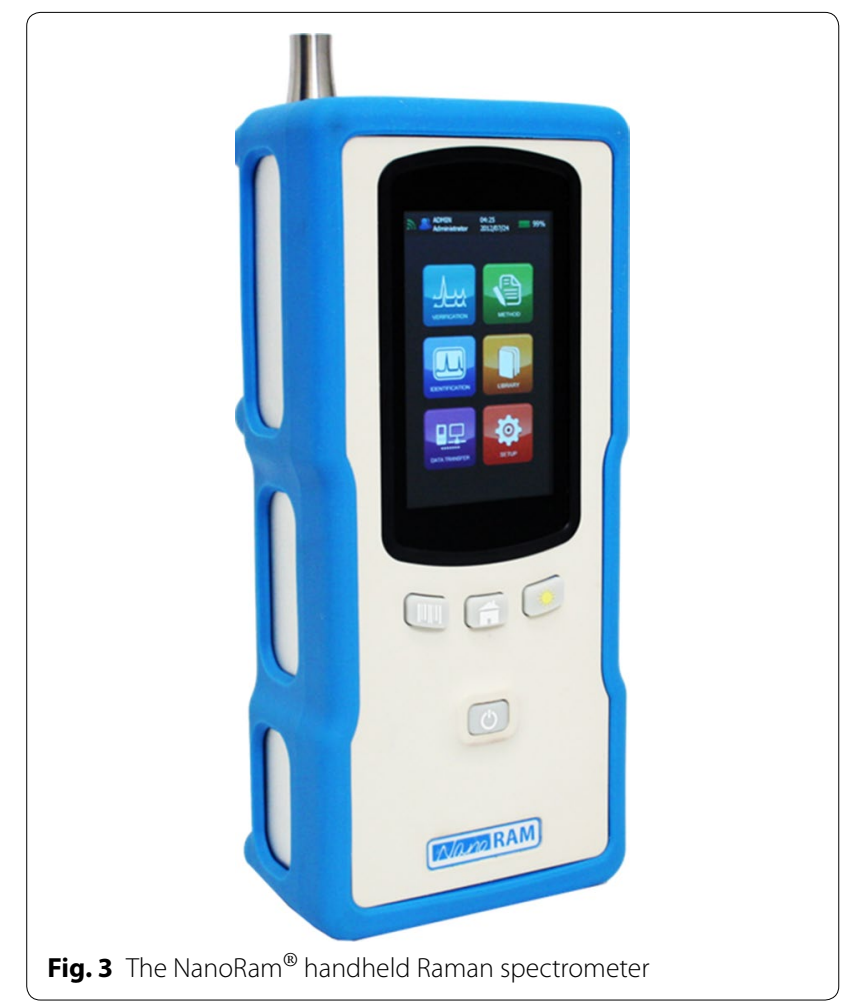

see Additional file 3). Match-or-fail comparison decisions were performed by the built-in software. Tablets (remaining inside the transparent blisters) were placed in front of the laser. Raman bands [Wave number $\left(\mathrm{cm}^{-1}\right)$ ] can be assigned to corresponding functional groups. The Raman characteristic frequencies of organic molecules and inorganic compounds have been described elsewhere [38-40]. The main outcomes of the test of a sample are a 'match or fail' result. This match-or-fail outcome is based on the $\mathrm{p}$ value automatically calculated by the handheld RS between the comparator (the reference spectrum) and the spectra of the sample under investigation.

\section{Study design and statistical methods}

Where appropriate, the standards for reporting of diagnostic accuracy studies (STARD) were followed [41] (Additional file 4). To determine the sensitivity and specificity of the handheld device in the identification of anti-malarial drugs, a two-gate reversed-flow design was applied [42]. The index test (Raman spectroscopy performed by the NanoRam ${ }^{\circledR}$ handheld spectrometer) and reference standard (thin layer chromatography and high performance liquid chromatography with ultraviolet photo diode array detection) were performed in reverse order. Reversing the order in which the index test and reference standard are conducted will not change the estimates of diagnostic accuracy. This type of design was chosen because of practical reasons since the samples were evaluated in another study already [21], and the RS was not yet available in our laboratory. In the preferable one-gate design, cases and controls are sampled from the same pool (anti-malarial drug collection); this was however not possible due to a lack of 'cases' (falsified drugs), thus a two-gate design was necessary (see below). To achieve sufficient power for the diagnostic accuracy calculations, the sample size was calculated as described in the sample size methods by Flahault et al. [43]. When the prevalence of poor quality drugs is less than $50 \%$, two assumptions ought to be made: the expected specificity (or sensitivity) values of the new diagnostic test, and the minimum acceptable lower confidence limit. For the NanoRam ${ }^{\circledR}$, two studies showed high sensitivity and specificity, but exact numbers were not reported [24, 25].

Assuming that the specificity will be high, at the minimal acceptable confidence limit of 0.7 (together with the required probability which was set here at 0.95 that this limit is not violated), the minimum number of falsified or poor-quality samples required is 24 [43]. The prevalence of poor-quality drugs in Gabon is $0.5 \%$ [ $(95 \% \mathrm{CI}$ $0.08-1.84 \%$ ) [21]. Using the prevalence of $0.5 \%$, the number of controls would be 199, using the equation Ncontrols $=$ Ncases $\times[(1-$ Prevalance $) /$ Prevalence $]$. The controls come from the same pool as the cases, thus the definite sample size is 223. Since the reference test was already conducted before the index test, it was known that only two samples were of poor quality [21]. Therefore, $24-2=22$ extra controls were added ("falsified anti-malarial drugs": in this model paracetamol $500 \mathrm{mg}$ was used). This two-gate model is an accepted design in the early investigation of a new diagnostic test [42], it has, however, been criticized for leading to inflated estimates of accuracy. Paracetamol was used since this product has been sold frequently as being an anti-malarial drug in South East Asia [44] and is readily available.

Data was analysed using SPSS (Version 21.0, IBM, NY, USA). The results of each diagnostic test of every sample were recorded in Excel and SPSS. The diagnostic accuracy was defined by sensitivity and specificity with $95 \%$ confidence intervals (CIs), which were computed as by standard literature $[45,46]$. A cross tabulation of the index text results by the results of the reference test was conducted.

\section{Results}

In this study, a total of 289 anti-malarial drugs were tested (Fig. 1). The index test was conducted within 8 months after the reference test. All samples were tested while remaining in their transparent blisters, except for DHA-PQ tablets $(\mathrm{n}=32,11 \%)$ : the blisters 
were transparent but the tablets have a thick blue coating resulting in a lack of penetration of the laser. These tablets were broken into half with a pill splitter, and subsequently tested. On average, a reference spectrum of an anti-malarial drug (20 runs) could be created within 3.5 (min-max: 3-6) minutes. The average time to conduct a match/fail analysis for one sample was 15: $10 \mathrm{~s}$ of entering data (name and sample number of the drug under investigation) and $5 \mathrm{~s}$ for scanning the drug sample and obtaining a match/fail result. In comparison, the semiquantitative layer chromatography technique used by the GPHF MiniLab ${ }^{\circledR}$ costs on average approximately $45 \mathrm{~min}$ processing time per sample.

\section{Precision test of the NanoRam spectrometer}

To investigate the capability of the NanoRam spectrometer to produce reproducible results, a match/fail analysis using a reference tablet was compared with the reference spectrum of the same sample. All the precision tests were conducted under the same circumstances and in duplicate. AL, DHA-PQ, Q, SP, AS-SP and paracetamol were utilized in different strengths. Table 2 depicts the results of the precision tests, Figs. $4 \mathrm{a}-\mathrm{d}$ and $5 \mathrm{a}$, b show examples of the precision test. Important to note is that the results of the match/fail scans are adjusted for the concentration of API in the tablet. For example, a match/fail test of AL 40/240 mg tablet matched the NanoRam's reference spectrum of AL 20/120 mg tablet. In strict sense, this should be a "fail". However, the NanoRam spectrometer only measures the concentration of the API in the tablet, and does not take into account tablet size or total weight, which may differ between different strengths of the same drug. In this particular case, the $40 / 240 \mathrm{mg}$ dosage contained the same concentration of API as the $20 / 120 \mathrm{mg}$ tablet, but the tablet was twice as big.

\section{Diagnostic accuracy of the RS}

To investigate the sensitivity and specificity of the device, different comparison scenarios to assess the ability of the RS to discriminate between different samples were evaluated. First, the diagnostic accuracy of the RS to correctly identify the API in the anti-malarial drug was determined. The 289 anti-malarial drugs plus additional fakes (22 paracetamol $500 \mathrm{mg}$ tablets) were analysed with the RS. The sensitivity and specificity were $100 \%$ (95\% CI 94.9-100\%) and 96.2\% (95 \% CI 92.3-99.0\%) respectively (Table 3). The falsified AL sample was correctly identified as having no API inside the tablets (Fig. 6). The suspected SP sample which failed the TLC test, was demonstrated with HPLC to contain the stated API, but the amount was approximately halve of the dose. The API was not identified by the NanoRam and thus "failed" the test (Fig. 7). However, the device suggested the API SP as closely related to the generated spectrum. 11 samples of SP "failed" the RS test, but passed the reference test. These 11 SP samples failed the RS test again in the subsequent round. The device suggested the API SP as closely related to the generated spectrum. Difficulty in using Raman spectroscopy in identifying SP has been previously reported [47]. A reason for this is the high fluorescence of SP itself. The 22 paracetamol tablets were all correctly identified as being a non-malarial drug.

\section{Comparison of different lots of the same product}

$\mathrm{AL}, \mathrm{Q}, \mathrm{SP}$ were used in this test. One batch of AL (Coartem, Novartis, Batch: X1639) was used to generate a Raman reference spectrum. This reference spectrum was compared to samples of the same batch (X1639), and 35 samples of 15 selected other batches of the same manufacturer Novartis. All samples matched to the comparator batch. For SP and Q, no differences between different lots of the same product could be identified.

\section{Comparison of similar products from different manufacturers}

The capacity of the RS to discriminate between similar products from different pharmaceutical companies was also investigated (Table 1). The RS could not discriminate between products with the same API from different manufacturers.

Table 2 Precision tests

\begin{tabular}{llll}
\hline Sample & $\begin{array}{l}\text { Number of } \\
\text { reference samples }\end{array}$ & $\begin{array}{l}\text { Number of samples } \\
\text { matching signature }\end{array}$ & $\begin{array}{l}\text { Percentage } \\
\text { of match (\%) }\end{array}$ \\
\hline Artemether-lumefantrine 20/120, 40/240, $80 / 480 \mathrm{mg}$ & 72 & 72 & 100 \\
Quinine sulphate $300 \mathrm{mg}$ & 35 & 35 & 100 \\
Dihydroartemisinin-piperaquine $40 / 320 \mathrm{mg}$ & 12 & 12 & 100 \\
Artesunate-sulfamethoxypyrazine-pyrimethamine & 14 & 14 & 100 \\
$\quad$ 100/250/12,5 mg & 48 & 48 & 100 \\
Paracetamol $500 \mathrm{mg}$ & 48 & \\
\hline
\end{tabular}




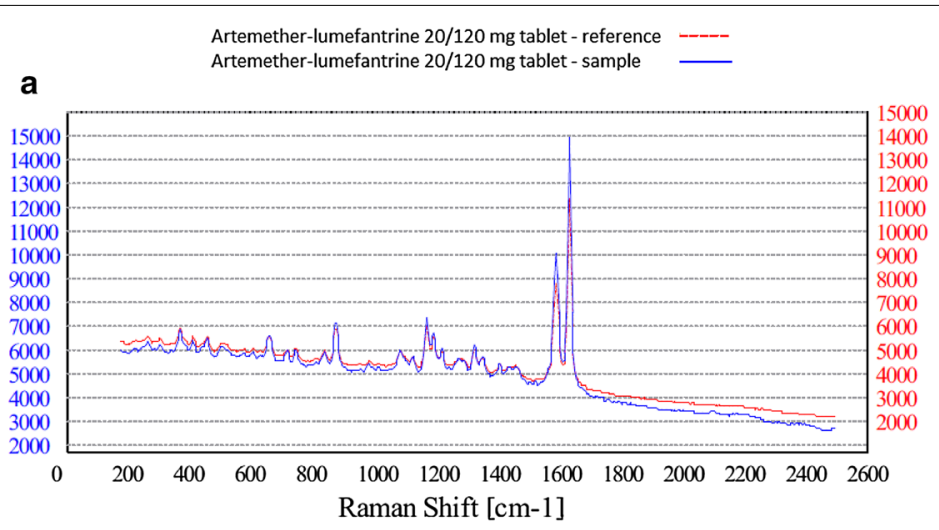

Dihydroartemisinin-piperaquine phosphate $40 / 320 \mathrm{mg}$ tablet - reference -----Dihydroartemisinin-piperaquine phosphate $40 / 320 \mathrm{mg}$ tablet - sample

b

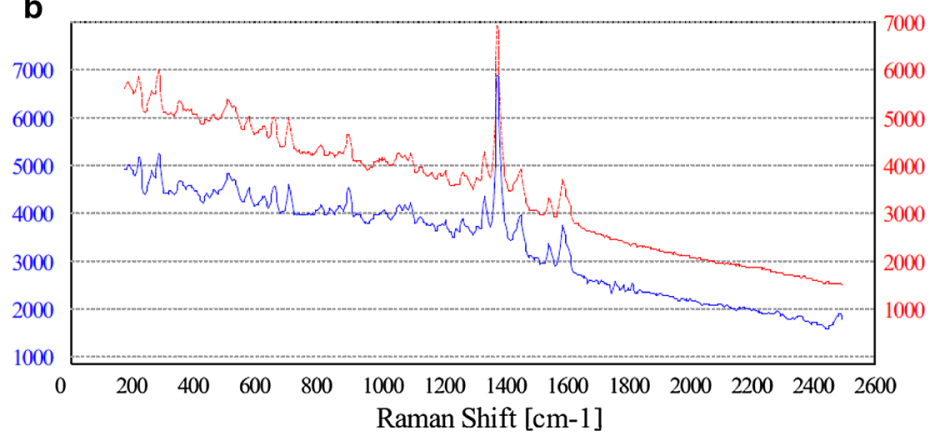

Quinine $250 \mathrm{mg}$ tablet - reference ----Quinine $250 \mathrm{mg}$ tablet - sample

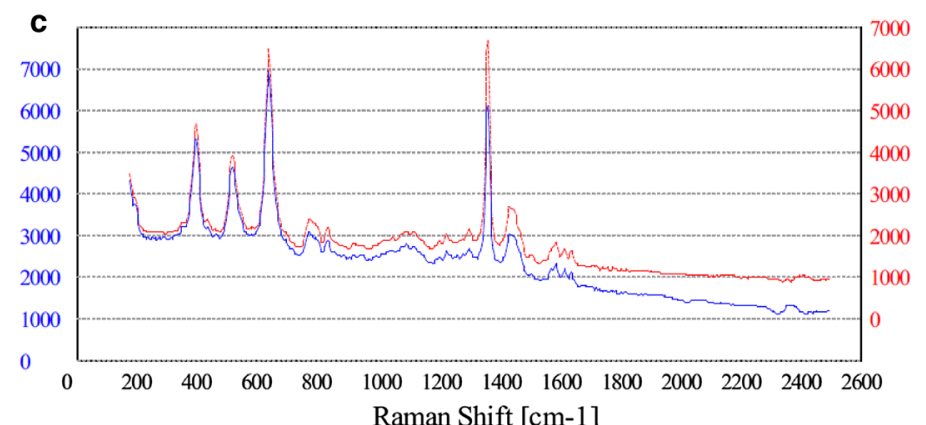

Raman Shift [cm-1]

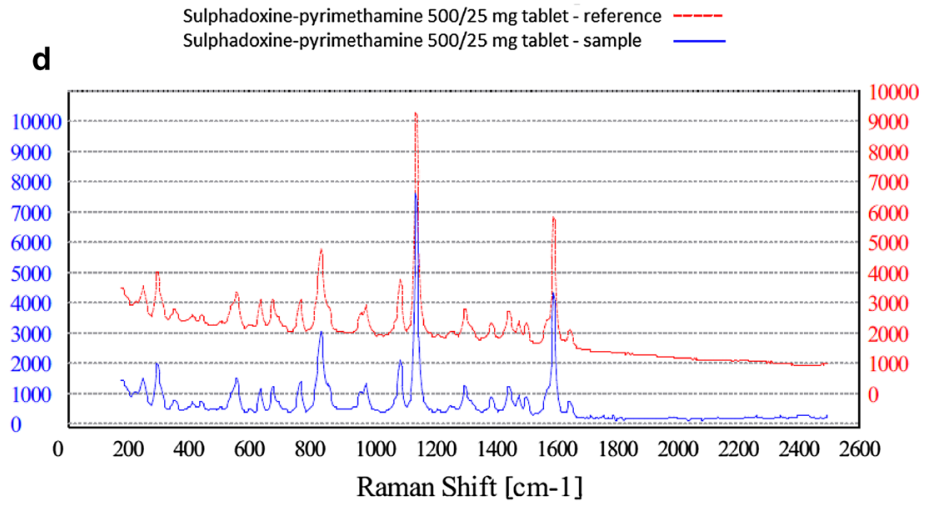

Fig. 4 Raman spectroscopy precision test results for a artemether lumefantrine 20/120 mg. b Dihydroartemisinin-piperaquine c quinine sulphate d sulfadoxine-pyrimethamine 


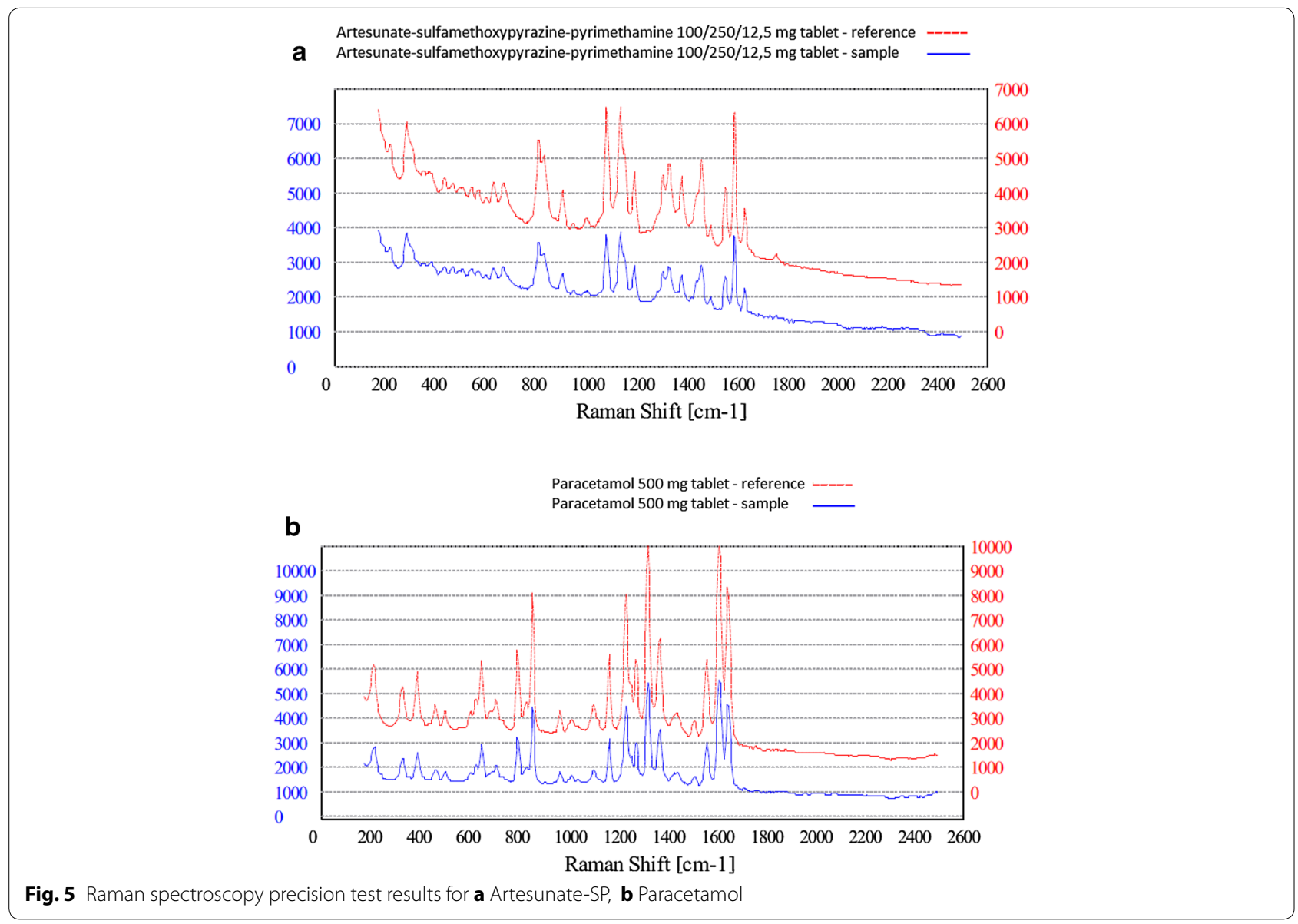

Table 32 × 2 Table Raman spectroscopy vs. thin-layer chromotography

\begin{tabular}{lllr}
\hline & $\begin{array}{l}\text { Falsified/cases } \\
\text { (fail TLC) }\end{array}$ & $\begin{array}{l}\text { Non-falsified/controls } \\
\text { (pass TLC) }\end{array}$ & Total \\
\hline Fail RS & $24(\mathrm{TP})$ & $11(\mathrm{FP})$ & 35 \\
Pass RS & $0(\mathrm{FN})$ & $276(\mathrm{TN})$ & 276 \\
Total & 24 & 287 & 311 \\
\hline
\end{tabular}

$T P$ true positive, $F P$ false positive, $F N$ false negative, $T N$ true negative, $R S$ Raman spectroscopy, $T L C$ thin-layer chromotography

\section{Discussion}

This study represents the first evaluation of the diagnostic accuracy of the NanoRam ${ }^{\circledR}$ spectrometer to identify and discriminate between anti-malarial drugs. The results suggest that the handheld NanoRam ${ }^{\circledR}$ spectrometer has a high sensitivity and specificity to identify antimalarial drugs. All falsified anti-malarials were detected by the RS. Some samples $(n=11$, only SP) contained the stated API, but still failed the test ("false positives"). The results suggest that the NanoRam ${ }^{\circledR}$ can be used to screen large quantities of anti-malarial drugs in a fast and non-destructive way, but caution is required when screening SP tablets. Minimal training was required and agreement between the tests was $100 \%$. Reference standards for the NanoRam ${ }^{\circledR}$ are not provided with the device but can be easily created and shared between users around the globe.

\section{Strengths and limitations}

The major strength of the present study is the large number of different random collected anti-malarial samples, which enabled us to investigate and create different reference spectra for the anti-malarial drugs. Another strength is that the sample size was sufficient to calculate the diagnostic accuracy. A major limitation of this study is that the reference standard is a semi-quantitative method, and that the sensitivity of the reference method is limited [48]. This means that false negatives might be present. The probability of false positives has been reduced, by analysing the samples failing TLC also with HPLC. It was not possible to analyse all samples with HPLC because the funds for this study were insufficient (HPLC of all samples costs approximately 14,000€). An important next step for further research should be an 

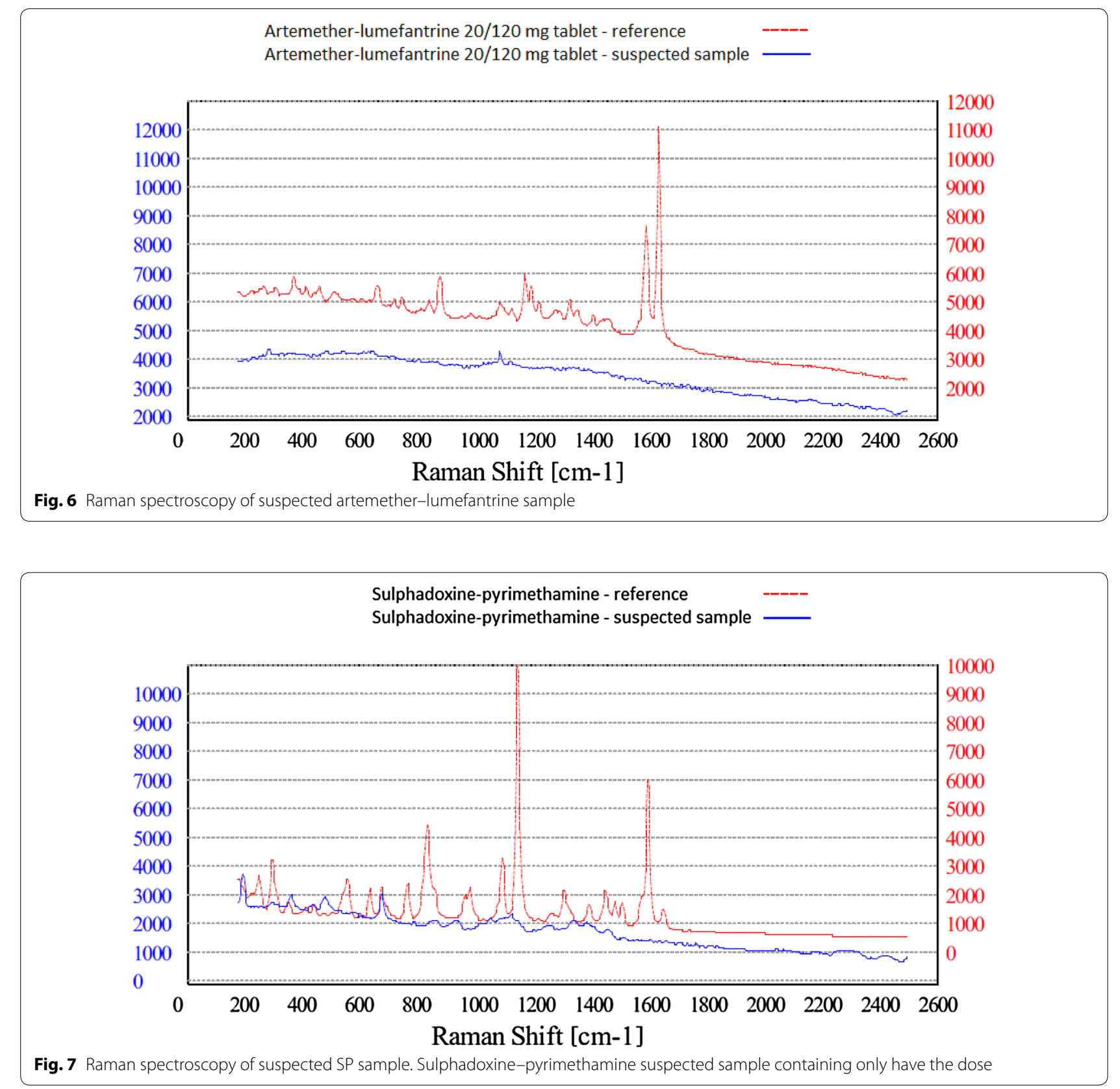

evaluation of the diagnostic accuracy of the handheld RS compared to the reference standard HPLC. Another limitation of our study is that we had a number of missing reference samples and had to exclude 143 anti-malarial samples. Moreover, the number of 'true' falsified antimalarials was small, and an extra case group (paracetamol tablets) had to be added, which is a source of bias and might have led to an overestimation of the diagnostic accuracy. Another potential source of bias is that the investigator could not be blinded for the results of the reference test; this risk is minimal because the device provides a 'pass' or 'fail' with a $p$ value, leaving little room for interpretation errors. Lastly, a limitation of this study is that the ability of the handheld RS device to discriminate between different dosage strengths as an indicator of the quality of anti-malarial drugs was not investigated. The number of different samples with different dosages for this analysis was insufficient. The ability to differentiate between dosages is important since products with reduced APIs have been produced.

The handheld RS (NanoRam ${ }^{\circledR}$ ) device is commercially available but expensive. However, it could be 
cost-effective to have a device as a medicine regulatory authorities since it can reduce the number of products that will undergo reference testing in specialized laboratories overseas, which is time-consuming and even more expensive.

\section{Conclusion}

The results have demonstrated that Raman spectroscopy performed by the NanoRam ${ }^{\circledR}$ has a high sensitivity and specificity to identify and discriminate between anti-malarial drugs. In future medicine quality surveys, a handheld RS, preferably in combination with reference methods such as HPLC, may become the preferred method to assess the quality of large quantities of antimalarial drugs throughout the supply chain. Hence, a handheld RS can be a valuable tool in the ultimate goal of malaria elimination.

\section{Additional files}

Additional file 1. The costs of this study.

Additional file 2. NanoRam ${ }^{\circledR}$ product specifications.

Additional file 3. Library methods figures.

Additional file 4. STARD checklist.

\begin{abstract}
Abbreviations
ACT: artemisinin-based combination therapy; AL: artemether-lumefantrine; AMC: Academic Medical Center; API: active pharmaceutical ingredient; CERMEL: Centre de Recherches Médicales de Lambaréné; GPHF: The Global Pharma Health Fund; HPLC: high-performance liquid chromatography; INN: international non-proprietary name; MEDQUARG: medicine quality assessment reporting guidelines; RS: Raman spectrometer; SP: sulfadoxinepyrimethamine; TLC: semi-quantitative thin-layer chromatography; USP: US Pharmacopeia; UV: ultraviolet-visible; WHO: World Health Organization.
\end{abstract}

\section{Authors' contributions}

BJV and MPG conceived the study. BJV and DK collected the samples. BJV and JMG conducted the thin-layer chromatography tests. BJV performed the statistical analysis and wrote the first draft of the manuscript. BJV conducted the analysis with the NanoRam ${ }^{\circledR}$. SGV, EBB, AST and JB contributed to the manuscript. EBB and AST wrote the French abstract. MPG, AST and MVV supervised the study and contributed to the writing of the final version of the manuscript. All authors have agreed to be fully accountable for all aspects of this work. All authors read and approved the final manuscript.

\section{Author details}

${ }^{1}$ Department of Infectious Diseases, Division of Internal Medicine, Center of Tropical Medicine and Travel Medicine, Academic Medical Center, University of Amsterdam, Meibergdreef 9, PO Box 22700, 1100 DE Amsterdam, The Netherlands. ${ }^{2}$ Centre de Recherches de Médicales de Lambaréné (CERMEL), Albert Schweitzer Hospital, Lambaréné, Gabon. ${ }^{3}$ Institute of Tropical Medicine, University of Tübingen, Tübingen, Germany. ${ }^{4}$ Pharmaceutical Technology and Biopharmacy, Utrecht University, Utrecht, The Netherlands.

\section{Acknowledgements}

We would like to thank Roseline Koumba and Brigitte Migombe of Centre de Recherches Medicales de Lambaréné (CERMEL) for their supportive field assistance. Dr. H. Kaur for conducting the HPLC tests of one AL-sample and one SP-sample, and the manufacturers of the anti-malarial drugs for providing reference samples.

\section{Competing interests}

The authors declare that they have no competing interests.

Received: 8 October 2015 Accepted: 5 March 2016

Published online: 15 March 2016

\section{References}

1. Newton PN, Lee SJ, Goodman C, Fernandez FM, Yeung S, Phanouvong S, et al. Guidelines for field surveys of the quality of medicines: a proposal. PLoS Med. 2009;6:e52.

2. Chaccour C, Kaur H, Del Pozo JL. Falsified antimalarials: a minireview. Expert Rev Anti Infect Ther. 2015;13:505-9.

3. Tabernero P, Fernandez FM, Green M, Guerin PJ, Newton PN. Mind the gaps-the epidemiology of poor-quality anti-malarials in the malarious world-analysis of the WorldWide antimalarial resistance network database. Malar J. 2014;13:139.

4. Almuzaini T, Choonara I, Sammons H. Substandard and counterfeit medicines: a systematic review of the literature. BMJ Open. 2013;3:e002923.

5. Nayyar GM, Breman JG, Newton PN, Herrington J. Poor-quality antimalarial drugs in southeast Asia and sub-Saharan Africa. Lancet Infect Dis. 2012;12:488-96.

6. Newton PN, Amin AA, Bird C, Passmore P, Dukes G, Tomson G, et al. The primacy of public health considerations in defining poor quality medicines. PLoS Med. 2011;8:e1001139.

7. Newton PN, Green MD, Mildenhall DC, Plancon A, Nettey H, Nyadong $L$, et al. Poor quality vital anti-malarials in Africa - an urgent neglected public health priority. Malar J. 2011;10:352.

8. Newton PN, Tabernero P, Dwivedi P, Culzoni MJ, Monge ME, Swamidoss I, et al. Falsified medicines in Africa: all talk, no action. Lancet Glob Health. 2014;2:e509-10.

9. WHO. Malaria Factsheet No 94. Geneva: World Health Organization; 2016. Available at: http://www.who.int/mediacentre/factsheets/fs094/en/. Accessed 29 Feb 2016.

10. van Vugt M, van Beest A, Sicuri E, van Tulder M, Grobusch MP. Malaria treatment and prophylaxis in endemic and nonendemic countries: evidence on strategies and their cost-effectiveness. Future Microbiol. 2011;6:1485-500.

11. Visser BJ, van Vugt M, Grobusch MP. Malaria: an update on current chemotherapy. Expert Opin Pharmacother. 2014;15:2219-54.

12. Visser BJ, Wieten RW, Kroon D, Nagel IM, Belard S, van Vugt M, et al. Efficacy and safety of artemisinin combination therapy (ACT) for nonfalciparum malaria: a systematic review. Malar J. 2014;13:463.

13. Grobusch MP, van Vugt M. Malaria therapy: where do we stand, what next? Future Microbiol. 2010;5:1447-9.

14. Kelesidis T, Falagas ME. Substandard/counterfeit antimicrobial drugs. Clin Microbiol Rev. 2015;28:443-64.

15. Renschler JP, Walters KM, Newton PN, Laxminarayan R. Estimated underfive deaths associated with poor-quality antimalarials in sub-saharan Africa. Am J Trop Med Hyg. 2015;92:119-26.

16. Tabernero P, Newton PN. The WWARN antimalarial quality surveyor. Pathog Glob Health. 2012;106:77-8.

17. White NJ, Pongtavornpinyo W, Maude RJ, Saralamba S, Aguas R, Stepniewska K, et al. Hyperparasitaemia and low dosing are an important source of anti-malarial drug resistance. Malar J. 2009;8:253.

18. Karunamoorthi K. The counterfeit anti-malarial is a crime against humanity: a systematic review of the scientific evidence. Malar J. 2014;13:209.

19. Global Pharma Health Fund E.V. GPHF-Minilab-Manuals. 2008. Available at: http://www.gphf.org/web/en/minilab/manuals.htm. Accessed 29-02-2016).

20. Global Pharma Health Fund E.V. GPHF-Minilab-Manuals. 2015. Available at: http://www.gphf.org/web/en/minilab/manuals.htm. Accessed 29 Feb 2016.

21. Visser BJ, Meerveld-Gerrits J, Kroon D, Mougoula J, Vingerling R, Bache E, et al. Assessing the quality of anti-malarial drugs from Gabonese pharmacies using the MiniLab(R): a field study. Malar J. 2015;14:273.

22. Degardin K, Roggo Y, Been F, Margot P. Detection and chemical profiling of medicine counterfeits by Raman spectroscopy and chemometrics. Anal Chim Acta. 2011;705:334-41. 
23. Kiehntopf M, Monch B, Salzer R, Kupfer M, Hartmann M. Quality control of cytotoxic drug preparations by means of Raman spectroscopy. Pharmazie. 2012;67:95-6.

24. Hajjou M, Qin Y, Bradby S, Bempong D, Lukulay P. Assessment of the performance of a handheld Raman device for potential use as a screening tool in evaluating medicines quality. J Pharm Biomed Anal. 2013;74:47-55

25. de Veij M, Vandenabeele P, Hall KA, Fernandez FM, Green MD, White NJ, et al. Fast detection and identification of counterfeit antimalarial tablets by Raman spectroscopy. J Raman Spectrosc. 2007;38:181-7.

26. Visser BJ. Antimalarial drug quality in Gabon. Netherlands Trial Regisitry (NTR) Number: 4341. Available at: http://www.trialregister.nl/trialreg/ admin/rctview.asp?TC=4341. Accessed 29 Feb 2016.

27. Visser BJ, Buijink AW, Grobusch MP. Reporting of medical research costs. Improving transparency and reproducibility of medical research. Methods Inf Med. 2014;53:329-31.

28. Bate R, Tren R, Mooney L, Hess K, Mitra B, Debroy B, et al. Pilot study of essential drug quality in two major cities in India. PLoS One. 2009;4:e6003.

29. loset JR, Kaur H. Simple field assays to check quality of current artemisinin-based antimalarial combination formulations. PLoS One. 2009;4:e7270

30. Kaur H, Green MD, Hostetler DM, Fernández FM, Newton PN. Antimalarial drug quality: methods to detect suspect drugs. Therapy. 2010;7:49-57.

31. Quinn MF. Relation of observer agreement to accuracy according to a two-receiver signal detection model of diagnosis. Med Decis Making. 1989;9:196-206.

32. Paudel A, Raijada D, Rantanen J. Raman spectroscopy in pharmaceutical product design. Adv Drug Deliv Rev. 2015;89:3-20.

33. Blevins RD, Plunkett R. Formulas for natural frequency and mode shape. J Appl Mech. 1980;47:461.

34. Kim HH. Endoscopic Raman spectroscopy for molecular fingerprinting of gastric cancer: principle to implementation. Biomed Res Int. 2015:670121.

35. Raman spectroscopy. European Pharmacopoeia (Ph. Eur.). 8th ed. European Directorate for the Quality of Medicines \& Health Care. Available at: https://www.edqm.eu/en/european-pharmacopoeia-8th-edition-1563. html Accessed 29 Feb 2016
36. Committee NP. Pharmacopoeia of the People's Republic of China. Part 2010, 1. p. 392-3

37. Reader J, Corliss CH, Wiese WL, Martin GA. Wavelengths and transition probabilities for atoms and atomic ions: part 1. Wavelengths, part 2. Transition probabilities. NSRDS-NBS. vol 68, 1. 1980.

38. Lin-Vien D, Colthup NB, Fateley WG, Grasselli JG. The handbook of infrared and Raman characteristic frequencies of organic molecules. Elsevier; 1991.

39. Nyquist RA, Kagel RO. Handbook of infrared and raman spectra of inorganic compounds and organic salts: infrared spectra of inorganic compounds. Academic press; 2012.

40. Nakamoto K. Infrared and Raman spectra of inorganic and coordination compounds. Wiley Online Library; 1986.

41. Bossuyt PM, Reitsma JB, Bruns DE, Gatsonis CA, Glasziou PP, Irwig LM, et al. The STARD statement for reporting studies of diagnostic accuracy: explanation and elaboration. Clin Chem. 2003;49:7-18.

42. Rutjes AW, Reitsma JB, Vandenbroucke JP, Glas AS, Bossuyt PM. Casecontrol and two-gate designs in diagnostic accuracy studies. Clin Chem. 2005;51:1335-41.

43. Flahault A, Cadilhac M, Thomas G. Sample size calculation should be performed for design accuracy in diagnostic test studies. J Clin Epidemiol. 2005;58:859-62.

44. Hall KA, Newton PN, Green MD, De Veij M, Vandenabeele P, Pizzanelli D, et al. Characterization of counterfeit artesunate antimalarial tablets from southeast Asia. Am J Trop Med Hyg. 2006;75:804-11.

45. Newcombe RG. Two-sided confidence intervals for the single proportion: comparison of seven methods. Stat Med. 1998;17:857-72.

46. Newcombe RG. Improved confidence intervals for the difference between binomial proportions based on paired data. Stat Med. 1998;17:2635-50.

47. Bate R, Tren R, Hess K, Mooney L, Porter K. Pilot study comparing technologies to test for substandard drugs in field settings. Afr J Pharm Pharmacol. 2009;3:165-70.

48. Bate R, Hess K. Anti-malarial drug quality in Lagos and Accra-a comparison of various quality assessments. Malar J. 2010;9:157.

\section{Submit your next manuscript to BioMed Central and we will help you at every step:}

- We accept pre-submission inquiries

- Our selector tool helps you to find the most relevant journal

- We provide round the clock customer support

- Convenient online submission

- Thorough peer review

- Inclusion in PubMed and all major indexing services

- Maximum visibility for your research

Submit your manuscript at www.biomedcentral.com/submit
() Biomed Central 